\title{
Inter-Turn Short-Circuit Failure of PMSM Indicator based on Kalman Filtering in Operational Behavior
}

\author{
Badr Mansouri ${ }^{1}$, Hicham Janati Idrissi ${ }^{2}$ and Audrey.Venon ${ }^{3}$ \\ ${ }^{1,2,3}$ Safran Electronics \& Defense (SAFRAN Group), Avionics Division, 100 Av. de Paris, Massy Cedex 91344, France \\ badr.mansouri@safrangroup.com \\ hicham.janati-idrissi@safrangroup.com \\ audrey.venon@safrangroup.com
}

\begin{abstract}
In the next twenty years traffic aircraft will be doubled. Thus, avionic devices will become more and more electric and the aircrafts become lighter in order to save more fuel. Thus, the more electric aircraft will face a great challenge that of the predictive maintenance of its electrical equipment. A key component of these devices is the Permanent Magnet Synchronous Motor (PMSM). In this article we are interested in one of the most recurrent failure of electric motor; that of the inter-turn short circuit failure (ISCF). The purpose of this study, therefore, is to develop an inter-turn short-circuit sensitive indicator. It's based on a linear Kalman filter for a healthy model to estimate residual voltage drops in the rotor reference $(d, q)$. The proposed study shows a high sensitive indicator to the inter-turn short-circuit fault even under external disturbances. As well, several features can result from it, especially the signal energy, spectral and statistical information, etc. These features can highlight aging laws that will be used as patterns for Prognosis and Health Management (PHM) of inter-turn short-circuit failure.
\end{abstract}

\section{INTRODUCTION}

The aeronautics industry is facing three major challenges: the reduction of its environmental impact, the air traffic increase and the one to maintain a high level of safety with complex systems in evolution, for equivalent costs. Predictive maintenance allows to answer to these issues. Systems, for which the life can be predicted, can be used for a longer time. This reduces the number of components used in the lifetime of an aircraft. Predicting failures also allow increasing the availability of aircrafts by avoiding unplanned downtime. Finally, monitoring the ageing of the aircraft allows optimizing maintenance and so to reduce

Badr Mansouri et al. This is an open-access article distributed under the terms of the Creative Commons Attribution 3.0 United States License, which permits unrestricted use, distribution, and reproduction in any medium, provided the original author and source are credited. costs.

PMSM drive is considered as one of the main components of electromechanical actuators for electrical flight control. In this context of study, we will focus on the diagnosis of the inter-turn short circuit fault of PMSM. Most works that have been carried out on this topic belonged to signal approach. In fact, these studies suppose that each fault is characterized by specific spectral signatures on the spectra of acquired signals. Among these schemes; Kyeong (2011) consists to survey the changes in the resistance and inductance of the fault phase. This implies to monitor the second-order harmonic in the q-axis current. So, by using extended Park's vector approach (Faiz, 2016), (Boileau, 2010), the second harmonic appears under the fault due to the negative component in the current space vector. In (Cira, 2016) a study based on Motor Current Signature Analysis, shows that it is possible to carry out fault detection by applying Fast Fourier Transform (FFT) to space vectors of stator current and voltage to get the negative \& positive harmonics. These show that their amplitudes are impacted significantly for given speed, load and short circuit severity level. However, the major disadvantage of these methods is that they work only at constant dq-axis current space vector, i.e. steady state. So, Urresty et al. (2011) propose the zero sequence voltage components (ZSVC) of the stator threephase voltages as a method to detect inter-turns short circuits in PMSM operating under transient conditions by analyzing the first-order harmonic given by zero sequence voltage. Conversely, this method requires an additional sensor for the voltage measurement. In addition to the frequency pattern of stator current, in (Liang, 2014) the diagnosis of PMSM introduces the frequency pattern of noise as a secondary criterion; hence, this noise measurement requires in an additional sensor, especially, a microphone. One of the easiest way to detect an ISCF, is to use magnitude differences in the stator currents (Sdiri, 2017), it presents a significant gap under inter-turn short circuit as proposed in (Hang, 2016). As well, inter-turn short circuit fault can be manifested in the trajectory of the 
current space vector based on Park's vector modulus (Alejandro, 2013). In fact, in healthy case, the trajectory is a circle with a constant magnitude. However, with the interturn short circuit fault the trajectory becomes an ellipse in steady states.

Many methods have been developed based on a prediction model or Kalman filter. Kiselev, Kuznietsov and Leidhold, (2017) have developed an algorithm using a general ARMAX model prediction of the current space vector based on a healthy model of PMSM, so the short circuit fault detection is carried out by comparing the predicted signal with measurements, hence, the error signal possesses a second-order harmonic, which can be detected. This approach also allows detecting the fault under nonstationary conditions in term of speed as well in steady state in terms of the q-axis current, i.e, constant load and determinist operating profile of load and speed. Also, even this indicator is sensitive to the second-order harmonic; this indicator may be disturbed by the presence of high order harmonics of space due to the magnetic saliency. Merraoui and Ferdjouni (2014) use an Extended Kalman Filters (EKF) to estimate the fault factors that are defined as the ratios of healthy turns to the total number of turns in each stator phase, the multi-model estimator can reduce the computational cost, but an EKF with eight variables state remains costly. We can also find many works using Kalman filter in steady states only to estimate motor parameters (Boileau, 2010), (Nahid, 2001).

The inter turn short circuit fault can be also monitored by using voltage control. In fact, to detect an ISCF, Youngkook (2007) compares the control voltages necessary for healthy motor and the control of the failed one. This method request a large lookup table depending on many operating point, which makes the computation very costly and the threshold tuning very complex.

Different methods have also been developed for induction motor only (Prasob, 2017), (Rehman, 2018). Among these methods; Alwodai et al. (2013) use a bi-spectrum modulation signal (MSB) to detect stator winding faults for induction motor. This analysis spectrum shows that MSB has the capability to accurately estimate modulation degrees and suppress the random and non-modulation components. So, the computation of MSB is very costly and concerns steady case. Ahamed et al. (2014) use a discrete Wavelet Transform using DB4 performed on the envelopes of the windowed steady-state current signatures only to detect the inter-turn short in the stator winding of an induction motor. In order to improve the fault detection task in steady state case, Zouzou et al. (2010) propose the use of Partial Relative Indexes (PRI) as fault indicators, based on the ratio between the amplitude average of each fault frequency and the amplitude average of healthy frequency. This approach has been applied on three-phase induction motors with broken bars and inter turn short-circuit. Different schemes have been developed in diagnosis of ISCF in PMSM by residual voltage. In fact, Lee, Jeong and Kim (2018) use residual voltage components (RVCs) that represent the difference between the measured stator voltages and the estimated stator voltages in the abc stationary reference frame. This involves an additional sensor to be used. Furthermore, only the fundamental frequency component is used to diagnose the ISCF while this information is not sufficient in case of magnetic saliency. Mazzoletti et al. (2017) use residual currents based on voltages measurement and stator currents estimated by using the state observer, so, it requires also a voltage sensor. Seokbae, Hyeyun and Sang (2016) establish a fault index of ISCF based on the residual voltage between healthy and faulty motor. But this relationship requires a priori knowledge of healthy motor behavior. This means that this approach is not dedicated to real time operating.

In practical cases the occurrence of inter-turn short circuit faults of PMSM is often accompanied by physical phenomena, especially magnetic saturation, salience (airgap), eccentricity, temperature and external disturbances. All of these phenomena can generate higher order harmonics and noise. Also, in practical cases, the operational profile is not often a steady state both in terms of current and speed, which does not make all steady methods applicable.

In this paper, we propose an approach based on residual voltage estimated by Linear Kalman Filter (LKF). This estimator is established on healthy model of PMSM in dq reference frame. Then, an indicator of ISCF severity is built by using the energy of the estimated residual voltage. Notice that, the residual voltage may occur among two kinds of faults, especially, inter-turn short circuit, and inverter failure. In this study, we focus only in the first one. The main advantages of the method proposed in this paper are as follows:

1. This method doesn't need any voltage sensor, it is based only on voltage set-points computed by the current loop control and Kalman estimator

2. This method does not need any reference signal of healthy case. The elaborated Kalman model gives directly the residual voltage in the faulty case.

3. This method is robust, because it considers all internal physical phenomena and external environment thank to Kalman estimator.

4. The energy criterion covers the spectrum of all frequencies, especially those due to the magnetic saliency that can disturb the second harmonic appearing in ISCF case.

5. This approach takes into-account the operational aspect of loads and speed profiles and it can be applied in real time. Hence, the indicator of ISCF can be computed by using a sliding window. 
6. Thanks to LKF filter, and the energy indicator, the overall computation cost remains very low.

An example of simulation is given in the last section to show the effectiveness of this diagnosis approach.

\section{PMSM MODEL WITH INTER-TURN SHORT-CIRCUIT \\ FAULT}

\section{NOMENCLATURE}

$v_{a b c f}$

$i_{a b c f}$

$v_{d q}$

$i_{d q}$

$i_{f}$

$R_{S}$

$L_{S}$

$M_{S}$

$R_{a b c f}$

$L_{a b c f}$

$L 1_{a b c f}$

$L 2_{a b c f}$

$\varphi_{a b c f}$

$\varphi_{m}$

$\theta_{e}$

$\mu$

$R_{f}$

Na2

Na1

$p$

$L_{d}$

$L_{q}$

$\Omega$

In this study, we suppose that only one phase of PMSM is under inter-turn short circuit fault (Phase $a$ as in Figure 1).

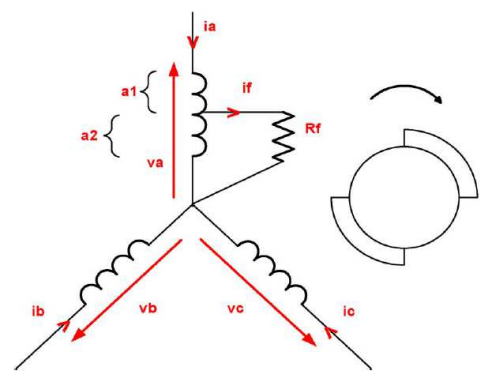

Figure 1. Inter-turn short circuit of PMSM (Phase a)

Many hypotheses are proposed in the literature, most of them don't consider the magnetic saliency. In fact, in this case, many space harmonics occurred. Thus, our faulty model can be described in the $a b c$-frame as follows:

$$
v_{a b c f}=R_{a b c f} \cdot i_{a b c f}+L_{a b c f}\left(\theta_{e}\right) \cdot \frac{d i_{a b c f}}{d t}+\frac{d \varphi_{a b c f}\left(\theta_{e}\right)}{d t}
$$

Where

$$
\begin{aligned}
& v_{a b c f}=\left[\begin{array}{llll}
v_{a} & v_{b} & v_{c} & 0
\end{array}\right]^{T}, i_{a b c f}=\left[\begin{array}{llll}
i_{a} & i_{b} & i_{c} & i_{f}
\end{array}\right]^{T} \\
& R_{a b c f}=\left[\begin{array}{cccc}
R_{s} & 0 & 0 & -\mu . R_{s} \\
0 & R_{s} & 0 & 0 \\
0 & 0 & R_{s} & 0 \\
-\mu . R_{s} & 0 & 0 & \mu . R_{s}+R_{f}
\end{array}\right] \\
& L_{a b c f}=L 1_{a b c f}+L 2_{a b c f}\left(\theta_{e}\right) \\
& L 1_{a b c f}=\left[\begin{array}{cccc}
L_{c y} & 0 & 0 & -\mu \cdot L_{s} \\
0 & L_{c y} & 0 & \mu \cdot M_{S} \\
0 & 0 & L_{c y} & \mu \cdot M_{S} \\
-\mu . L_{S} & \mu \cdot M_{S} & \mu \cdot M_{S} & \mu^{2} L_{S}
\end{array}\right] \\
& L_{c y}=L_{S}-M_{S} \\
& M_{S}=-\frac{1}{2} L_{S} \\
& L 2_{a b c f}\left(\theta_{e}\right)=\left[L 21_{a b c f}\left(\theta_{e}\right) \quad L 22_{a b c f}\left(\theta_{e}\right)\right] \\
& L 21_{a b c f}\left(\theta_{e}\right)=\left[\begin{array}{c}
\cos \left(2 \cdot \theta_{e}\right) \\
(1-\mu) \cdot \cos \left(2 \cdot \theta_{e}-2 \pi / 3\right) \\
(1-\mu) \cdot \cos \left(2 \cdot \theta_{e}+2 \pi / 3\right) \\
0
\end{array}\right. \\
& L 22_{a b c f}\left(\theta_{e}\right)=\left[\begin{array}{cc}
(1-\mu) \cdot \cos \left(2 \cdot \theta_{e}+2 \pi / 3\right) & 0 \\
\cos \left(2 \cdot \theta_{e}\right) & \mu \cdot \cos \left(2 \cdot \theta_{e}-2 \pi / 3\right) \\
\cos \left(2 \cdot \theta_{e}-2 \pi / 3\right) & \mu \cdot \cos \left(2 \cdot \theta_{e}+2 \pi / 3\right) \\
\mu \cdot \cos \left(2 \cdot \theta_{e}+2 \pi / 3\right) & \mu^{2} \cdot \cos \left(2 \cdot \theta_{e}\right)
\end{array}\right] \\
& \varphi_{a b c f}\left(\theta_{e}\right)=\varphi_{m} \cdot\left[\begin{array}{c}
\sin \left(\theta_{e}\right) \\
\sin \left(\theta_{e}-2 \pi / 3\right) \\
\sin \left(\theta_{e}+2 \pi / 3\right) \\
-\mu \cdot \sin \left(\theta_{e}\right)
\end{array}\right]
\end{aligned}
$$

$\mu$ is the fault severity given by the ratio between turns in fault $\mathrm{Na2}$, and the total number of turns in the involved winding given by $\mu=N a 2 /(N a 1+N a 2)$.

\section{ISCF DIAGNOSIS BASED ON KALMAN FILTER}

\subsection{Problem statement}

In this study, the diagnosis of Inter-turn short circuit fault of PMSM consists in the estimation of residual voltage drop between applied voltage on healthy motor and the one with ISCF. Prior to give Kalman filter; let's give dynamic linear model of healthy PMSM in $d q$ frame reference.

$$
\left\{\begin{array}{l}
V_{d}=R_{s} \cdot i_{d}+L_{d} \frac{d i_{d}}{d t}-L_{q} \cdot p \cdot \Omega \cdot i_{q} \\
V_{q}=R_{s} \cdot i_{q}+L_{q} \frac{d i_{q}}{d t}+L_{d} \cdot p \cdot \Omega \cdot i_{d}+\Omega \cdot k_{m}
\end{array}\right.
$$

Where $k_{m}=p \cdot \varphi_{m}$. Now let's consider the following hypotheses:

- The inter-turn short-circuit fault generates an additional residual voltages applied to the motor. Let's call this voltage gap; $\Delta V_{s c}$.

- The inverter has two kinds of intrinsic residual voltages; the first one is generated by the dead timeouts $V_{\text {Timeout }}($ Cathelin, 2012), the second one is due to the switching and conduction losses $V_{\text {switch }}$ (Leboeuf, 2012). Thus the total residual voltage of the inverter is given by: 


$$
V_{\text {inverter }}=V_{\text {Timeout }}+V_{\text {switch }}
$$

Hence, the overall residual voltage in the presence of ISCF is given by:

$$
V_{g}=\Delta \mathrm{V}_{s c}+\mathrm{V}_{\text {inverter }}
$$

By taking into-account the residual voltage, the dynamical model of PMSM (2) becomes:

$$
\left\{\begin{array}{l}
V_{d}+V_{d g}=R_{s} \cdot i_{d}+L_{d} \frac{d i_{d}}{d t}-L_{q} \cdot p \cdot \Omega \cdot i_{q} \\
V_{q}+V_{q_{g}}=R_{s} \cdot i_{q}+L_{q} \frac{d i_{q}}{d t}+L_{d} \cdot p \cdot \Omega \cdot i_{d}+\Omega \cdot k_{m}
\end{array}\right.
$$

So, for a given currents, speed and ISCF severity level, the voltage residues $V_{d_{g}}$ and $V_{q_{g}}$ are considered stationary.

\subsection{Structured residue estimation by using LKF}

To estimate a residue by using Kalman filter, this one shall be augmented such that the state vector contains also residues according to the following state space model:

$$
\left\{\begin{array}{l}
\dot{x}(t)=A_{11} x(t)+A_{12} V(t)+B u(t)+M_{1} w(t) \\
\dot{V}(t)= \\
y(t)=C x(t)+v(t)
\end{array}\right.
$$

Where $V(t)$ is the residue and $w(t)$ is an external disturbance vector, $x(t), u(t)$ and $v(t)$ are respectively the state, input control and noise measurement. Thus, by using this Kalman structure, we can estimate the generated residual voltage to detect an inter-turn short circuit fault. So, we consider that this residue is constant (structured) and zero in the absence of failure. Hence, the main hypothesis here is to consider that the dynamics of both voltage drops in $d q$ frame, noted respectively $V_{d_{g}}$ and $V_{q_{g}}$, is an integral type added to unknown random signals (noises) $w_{d}(t)$ and $w_{q}(t)$ that perturb the state space with known spectral power densities (Maybeck. 1979):

$$
\left\{\begin{array}{l}
\dot{V}_{d_{g}}(t)=0+w_{d}(t) \\
\dot{V}_{q_{g}}(t)=0+w_{q}(t)
\end{array}\right.
$$

Finally, by using the previous dynamic model (5) of healthy motor, the hypothesis (7) and by taking into account parameter's uncertainties $\Delta R_{s}, \Delta L_{d}$ and $\Delta L_{q}$, that can be grouped as follows:

$$
\left\{\begin{array}{l}
\Delta V_{d}=-\left(\Delta R_{s} \cdot i_{d}+\Delta L_{d} \cdot \frac{d i_{d}}{d t}-\Delta L_{q} \cdot p \cdot \Omega \cdot i_{q}\right) \\
\Delta V_{q}=-\left(\Delta R_{s} \cdot i_{q}+\Delta L_{q} \cdot \frac{d i_{q}}{d t}+\Delta L_{d} \cdot p \cdot \Omega \cdot i_{d}\right)
\end{array}\right.
$$

We get the following Kalman estimators of residual voltages:

$$
\begin{aligned}
& \text { - } d \text { axis } \\
& \left\{\begin{array}{c}
\frac{d i_{d}(t)}{d t} \\
\frac{d V_{d g}(t)}{d t}
\end{array}\right]=\left[\begin{array}{cc}
-\frac{R_{s}}{L_{d}} & \frac{1}{L_{d}} \\
0 & 0
\end{array}\right]\left[\begin{array}{c}
i_{d}(t) \\
V_{d_{g}}(t)
\end{array}\right]+\left[\begin{array}{c}
\frac{1}{L_{d}} \\
0
\end{array}\right] U_{d}+\left[\begin{array}{cc}
\frac{1}{L_{d}} & 0 \\
0 & 1
\end{array}\right]\left[\begin{array}{c}
\Delta V_{d} \\
w_{d}(t)
\end{array}\right]
\end{aligned}
$$

$$
\begin{aligned}
& \text { - } \quad q \text { axis } \\
& \left\{\begin{array}{l}
{\left[\begin{array}{c}
\frac{d i_{q}(t)}{d t} \\
d V_{q_{g}}(t) \\
d t
\end{array}\right]=\left[\begin{array}{cc}
-\frac{R_{s}}{L_{q}} & \frac{1}{L_{q}} \\
0 & 0
\end{array}\right]\left[\begin{array}{c}
i_{q}(t) \\
V_{q_{g}}(t)
\end{array}\right]+\left[\begin{array}{c}
\frac{1}{L_{q}} \\
0
\end{array}\right] U_{q}(t)+\left[\begin{array}{cc}
\frac{1}{L_{q}} & 0 \\
0 & 1
\end{array}\right]\left[\begin{array}{c}
\Delta V_{q} \\
w_{q}(t)
\end{array}\right]} \\
y(t)=\left[\begin{array}{ll}
1 & 0] \cdot\left[i_{q}(t) \quad V_{q_{g}}(t)\right.
\end{array}\right]^{T}
\end{array}\right.
\end{aligned}
$$

Where the control inputs are defined as:

$$
\left\{\begin{array}{l}
U_{d}=V_{d}+L_{q} \cdot p \cdot \Omega \cdot i_{q} \\
U_{q}=V_{q}-L_{d} \cdot p \cdot \Omega \cdot i_{d}-\Omega . k_{m}
\end{array}\right.
$$

So, by supposing that the residual voltage of inverter is negligible, then, in the case where there is no ISCF in the motor, the gap voltages go down to zero, i.e. $\left|V_{d_{g}}(t)\right| \approx 0$ and $\left|V_{q_{g}}(t)\right| \approx 0$. Hence, to get $V_{d}$ and $V_{q}$ we can use directly the voltages set-points computed by the currentloop control. Thus, to detect and evaluate the severity level of an inter-turn short circuit of PMSM under any external conditions can be achieved by searching features in the residual estimated voltage $V_{d_{g}}(t)$ and $V_{q_{g}}(t)$. In the next section, we will discuss the different ways to use these signals through an example of simulation.

\subsection{Inter-turn short-Circuit indicator for PHM}

In operating condition, the profile of speed and current setpoints can be stochastic or determinist, it's depending on the function that PMSM shall perform in operating conditions (load and speed). Finding a fault indicator under these conditions is not trivial. In this study, we propose a generalized indicator that takes into account any determinist profile of operating points. Thus, it is convenient to look at the energy of the estimated drop voltage $V_{q_{g}}$ in order to include both the constant part and the oscillatory part. So, we consider the quantity expressed as follows

$$
\lambda(t)=\int_{0}^{t} V_{q_{g}}^{2} d \tau
$$

In order to be insensitive to the variability of operating point, this indicator must be normalized by speed and current as follows (Youngkook, 2007):

$$
\lambda(t)=\int_{0}^{t} \frac{V_{q_{g}^{2}}^{2}}{\Omega \cdot I_{q}} \cdot d \tau
$$

with that $\Omega . I_{q} \neq 0$. In the PHM context, this indicator can be set on a sliding window. In the next section, an example of simulation will be discussed to show the convenience of this criterion.

\section{EXAMPLE AND DISCUSSION}

The aim of this study is to build an ISCF indicator of severity level of PMSM; the so called the 'aging law' in the 
literature. In this example of simulation, let's consider the following PMSM parameters given by the Table 1.

Table 1. Parameters of simulated PMSM.

\begin{tabular}{|l|l|l|}
\hline Parameter & \multicolumn{1}{|c|}{ Description } & Value \\
\hline$R_{S}$ & stator resistance $[\Omega]$ & 1.65 \\
\hline$L_{S}$ & stator inductance $[\mathrm{mH}]$ & 2 \\
\hline$p$ & number of pole pairs & 8 \\
\hline$\varphi_{m}$ & rotor flux linkage $[\mathrm{mWb}]$ & 37.4 \\
\hline$U_{d c}$ & nominal voltage of the motor $[\mathrm{V}]$ & 40 \\
\hline$I_{d q}$ & nominal current of the motor $[\mathrm{A}]$ & 3 \\
\hline$R_{f}$ & Inter-turn short circuit resistance $[\mathrm{m} \Omega]$ & 15 \\
\hline
\end{tabular}

Prior to give the aging law, let's interpret the dynamic behavior of estimated residual voltages $V_{d_{g}}$ and $V_{q_{g}}$ for different configurations; at zero speed behavior and nonzero speed behavior.

\subsection{Zero Speed Behavior}

At zero speed, the $I_{d q}$ set-points are fixed at (0A, 3A). Then, the residual voltages $V_{d_{g}}$ and $V_{q_{g}}$ are estimated by Kalman estimator. Notice that in this case the rotor position is still constant at the initial position. Thus, the Figure 2 illustrates the evaluation of $V_{d_{g}}$ and $V_{q_{g}}$ for different electrical positions within $2 \pi$ range at the permanent state of current.

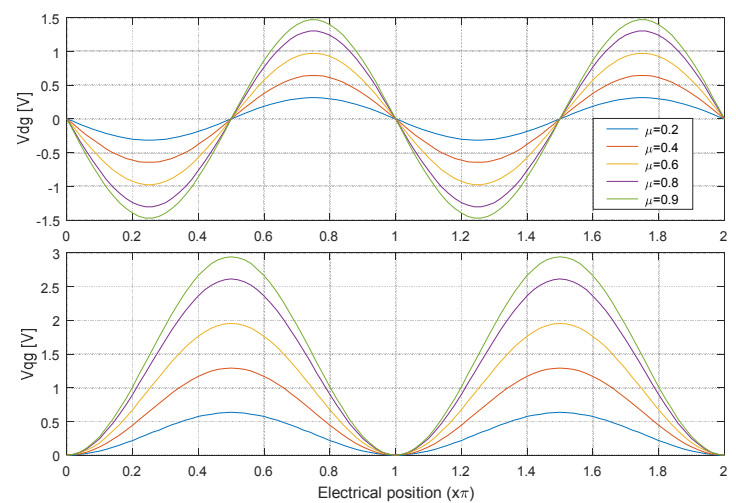

Figure 2. Residual voltages $V_{d_{g}}$ and $V_{q_{g}}$ caused by an ISCF at zero speed.

This result highlights several conclusions; the spatial frequency of the voltage drop evolves into $2 . \theta_{\mathrm{e}}$, the spatial average value of $V_{d_{g}}$ is zero, and the spatial average value of $V_{q_{g}}$ is proportional to the intern-turn short circuit severity level. This statement shows the continuous component of $V_{q_{g}}$ that presents a potential aging indicator adding to the amplitude of the second harmonic of the estimated signals.

\subsection{Non-Zero Speed Behavior}

In the case of No-Zero speed at several constant speed levels, Figure 3 illustrates $I_{d q}$ measurement for set-points $0 \mathrm{~A}$ and $1 \mathrm{~A}$ and Figure 4 shows the estimated residual voltages $V_{d_{g}}$ and $V_{q_{g}}$.

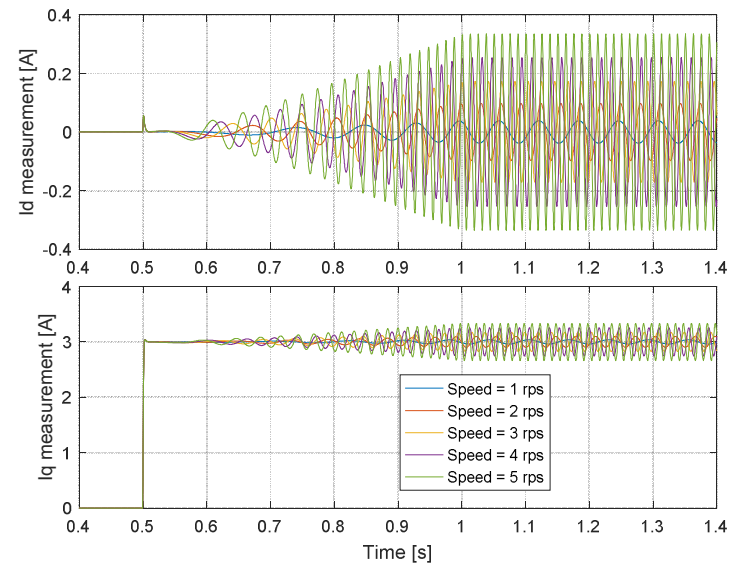

Figure 3. $I_{d q}$ measurements for different speeds under ISCF

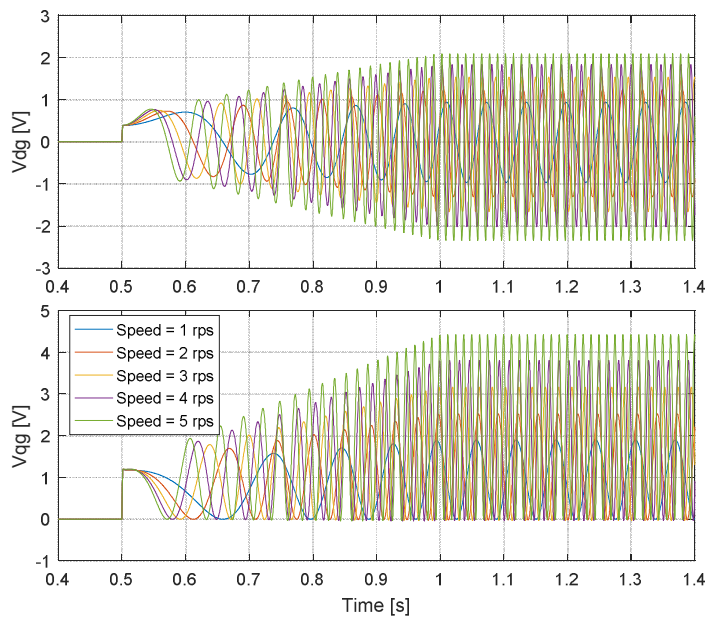

Figure 4. Estimated residual voltages $V_{d_{g}}$ and $V_{q_{g}}$ for different speeds level under ISCF

Hence, adding to the second harmonic depending on electrical position in both axes, $V_{q_{g}}$ presents a continuous component. We can also see that the magnitudes of both continuous and oscillatory components are depending on speed level. On the other hand, let's consider a speed profile consisting on a ramp then a constant, and a step of $I_{q}$ setpoint as shown in Figure 5. For several ISCF severities level, the Figure 6 shows $I_{d q}$ measurement and the Figure 7 gives the estimated residual voltage $V_{d_{g}}$ and $V_{q_{g}}$. 


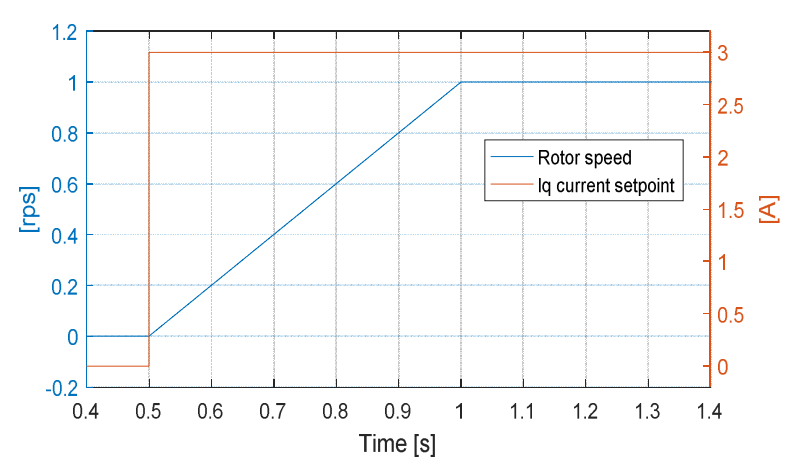

Figure 5. Speed and current profiles
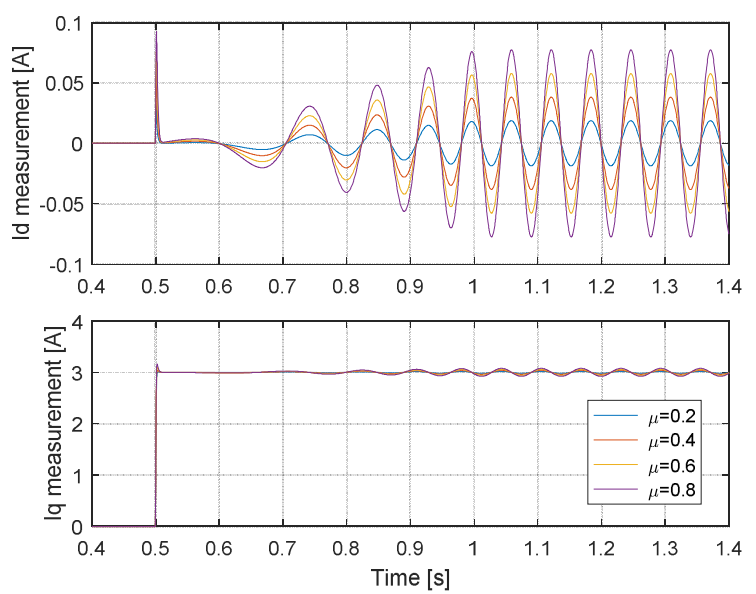

Figure 6. $I_{d q}$ under different ISCF severity level

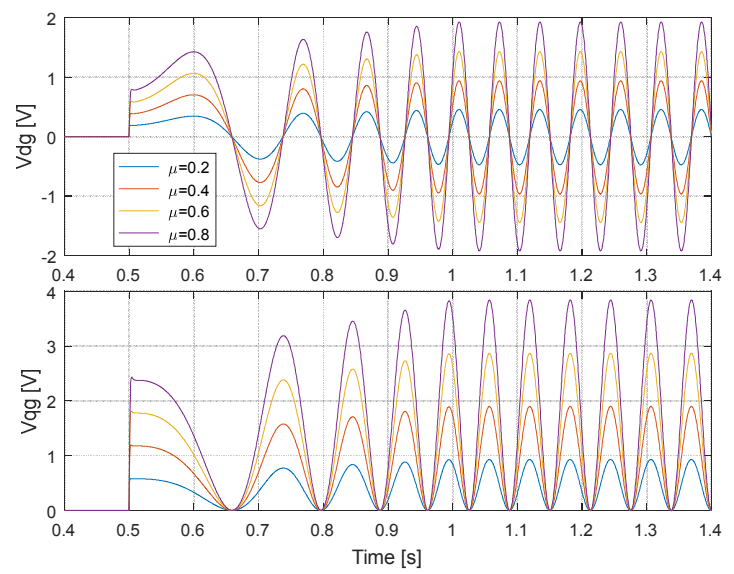

Figure 7. Estimated $V_{d_{g}}$ and $V_{q_{g}}$ under ISCF severities level

As well at non zero-speed, the magnitudes of both continuous and oscillatory components are depending on inter-turn short circuit severity level.

\subsection{Inter-turn short-Circuit indicator for PHM}

As shown in simulation result, the voltage drop $V_{q_{g}}$ presents continuous and oscillatory components that are depending on inter-turn short circuit severity level. Thus, by applying the criterion (13), the Figure 8 shows the evolution of the PHM indicator $\lambda$ according to inter-turn short circuit severity level.

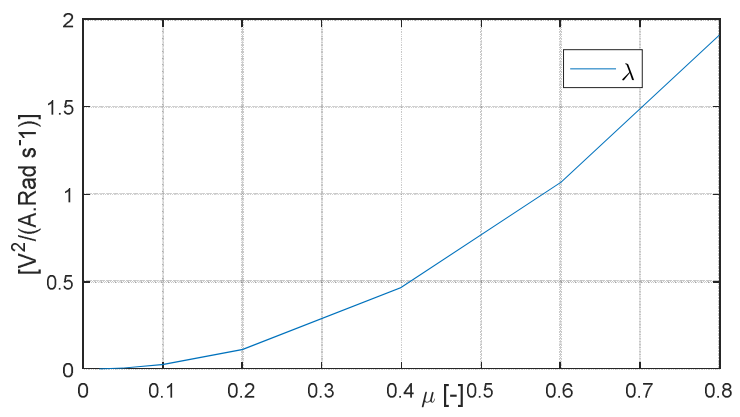

Figure 8. PHM indicator based on energy of estimated voltage drop $V_{q_{g}}$

This PHM indicator is strictly monotonous and very sensitive to severity level of ISCF for determinist profiles of speed and current.

\section{CONCLUSION}

In this work, the residual voltage engendered by the interturn short-circuit fault has been estimated directly by using an elaborated Kalman filter and based on healthy model of PMSM. Thanks to this estimator, we don't need any voltage sensor. These residues have been evaluated for different speed/current profiles and show a high sensitivity to the inter-turn short circuit fault. Indeed, this residual voltage has a continuous component and an oscillatory component depending on the electrical position. Thus, a criterion based on the residual voltage energy has been established for a deterministic speed/current profile, it shows a very high sensitivity to the severity failure and can be used as an indicator of PMSM aging in a PHM context. In view of this work, the aim would be to generalize this aging criterion for random speed/current profile.

\section{REFERENCES}

Ahamed, S. K., Sarkar, A., Mitra, M., \& Sengupta, S. (2014). Novel approach for detection of inter-turn short circuit of induction motor's stator winding through envelope analysis. 8th International Conference on Electrical and Computer Engineering.

Alejandro P. P., Martha C., Enciso, A., Javier, O. O., Jairo A., \& Penaranda, P. (2013) Stator fault diagnosis on squirrel cage induction motors by ESA and EPVA, Workshop on Power Electronics and Power Quality Applications, July, pp. 1-6. 
Alwodai, A., Shao, Y., Yuan, X., Ahmed, M., Gu, F., \& Ball,A.D. (2013). Inter-Turn Short Circuit Detection Based on Modulation Signal Bispectrum Analysis of Motor Current Signals Proceedings of the 19th International Conference on Automation \& Computing, Brunel University, London, UK.

Boileau, T., (2010). Contribution à la continuité de service des actionneurs synchrones à aimants permanentsTolérance au défaut de capteur mécanique-Detection de défauts électriques. Doctoral dissertation. Institut National Polytechnique de Lorraine.

Cathelin, J., (2012). Thèse Contribution à la commande sans capteur mécanique de la machine synchrone à aimants permanents. Doctoral dissertation. Supelec UPMC - Université Paris Sud.

Cira, F., Arkan, M., Gumus, B., \& Goktas, T. (2016). Analysis of stator inter-turn short-circuit fault signatures for inverter-fed permanent magnet synchronous motors. IECON - 42nd Annual Conference of the IEEE Industrial Electronics Society.

Faiz,. J., Exiri, A. H., \& Nejadi-Koti, H. (2016) CurrentBased Inter-Turn Short Circuit Fault Modeling in Permanent Magnet Synchronous Machine using Magnetic Equivalent Circuit Model, International Conference on Compatibility, Power Electronics and Power Engineering (pp. 265 - 270).

Hang, J., Ding, S., Zhang. J., Cheng, M., Chen, W., \& Wang, O. (2016). Detection of Inter-turn Short-circuit Fault for PMSM with Simple Fault Indicator, IEEE Transactions on Energy Conversion (pp. 1-1), Vol. PP, No. 99, June.

Kiselev, A., Kuznietsov, A., \& Leidhold, R. (2017). Model based online detection of inter-turn short circuit faults in PMSM drives under non-stationary conditions. 11th IEEE International Conference on Compatibility, Power Electronics and Power Engineering (CPEPOWERENG).

Kyeong, H. K. (2011). Simple Online Fault Detecting Scheme for Short-Circuited Turn in a PMSM Through Current Harmonic Monitoring. IEEE Transactions on Industrial Electronics (pp. 2565 - 2568) Vol. 58, No. 6, June,

Leboeuf. N., (2012). Contribution à l'étude des machines synchrones à aimants permanents en présence de défauts inter-spires - Modélisations, détections de défauts inter-spires. Doctoral dissertation. Université de Lorraine.

Lee, H. Jeong, H. and Kim, S. W. (2018). Diagnosis of Interturn Short-Circuit Fault in PMSM by Residual Voltage Analysis. International Symposium on Power Electronics, Electrical Drives, Automation and Motion (SPEEDAM), Amalfi, 2018, pp. 160-164.

Liang, Y. (2014). Diagnosis of inter-turn short-circuit stator winding fault in PMSM based on stator current and noise. IEEE International Conference on Industrial Technology (ICIT).
Maybeck, P. S. (1979). Maybeck. Stochastic Models, Estimation and Control. Volume 141-1, Mathematics in Science and Engineering.

Mazzoletti, M. A. Bossio, G. R. De Angelo, C. H. and Espinoza-Trejo, D. R. (2017). A Model-Based Strategy for Interturn Short-Circuit Fault Diagnosis in PMSM. IEEE Transactions on Industrial Electronics, vol. 64, no. 9 , pp. 7218-7228, Sept.

Merraoui, K. E., \& Ferdjouni, A. (2014). Detection of interturn short circuits in stator windings of im by extended Kalman filters. 22nd Mediterranean Conference on Control and Automation.

Nahid-Mobarakeh, B. (2001). Commande vectorielle sans capteur mécanique de machine synchrone à aimants: méthodes, convergence, robustesse, identification en ligne des paramètres. Doctoral dissertation. Institut National Polytechnique de Lorraine.

Prasob, K., Kumar, N. P., \& Isha, T. B. (2017). Inter-turn short circuit fault analysis of PWM inverter fed threephase induction motor using Finite Element Method. International Conference on Circuit ,Power and Computing Technologies (ICCPCT).

Rehman, A. U., Chen, Y., Zhao, Y., Cheng, Y., Zhao, Y., \& Tanaka, T. (2018). Detection of Rotor Inter-turn Short Circuit Fault in Doubly-fed Induction Generator using FEM Simulation. IEEE 2nd International Conference on Dielectrics (ICD).

Sdiri, F., Bensalem, Y., Trabelsi, H., \& Abdelkrim, M. N. (2017). Inter-turn short-circuit fault detection in the vectorial control PMSM drive. 18th International Conference on Sciences and Techniques of Automatic Control and Computer Engineering (STA).

Seokbae, M. Hyeyun J. and Sang Woo, K. (2016 ). Interturn short fault diagnosis of a PMSM using voltage residual components. IECON - 42nd Annual Conference of the IEEE Industrial Electronics Society, Florence, pp. 1513-1517.

Urresty, J. C., Riba, J. R., Saavedra, H., \& Romeral, L. (2011). Detection of Inter-Turns Short Circuits in Permanent Magnet Synchronous Motors Operating under Transient Conditions by means of the Zero Sequence Voltage. European Conference on Power Electronics and Applications (pp. 1 - 9), August.

Youngkook, L. (2007). A stator turn fault detection method and a fault tolerant operating strategy for interior PM synchronus motor drives in safety critical applications. Doctoral dissertation. Georgia Institute of Technology.

Zouzou, S. E., Sahraoui, M., Ghoggal, A., \& Guedidi, S. (2010). Detection of inter-turn short-circuit and broken rotor bars in induction motors using the Partial Relative Indexes: Application on the MCSA. The XIX International Conference on Electrical Machines ICEM. 